INFLAMMATORY BOWEL DISEASE

\title{
Production of adiponectin, an anti-inflammatory protein, in mesenteric adipose tissue in Crohn's disease
}

\author{
K Yamamoto, T Kiyohara, Y Murayama, S Kihara, Y Okamoto, T Funahashi, T lto, R Nezu, \\ S Tsutsui, J-I Miyagawa, S Tamura, Y Matsuzawa, I Shimomura, Y Shinomura
}

Gut 2005;54:789-796. doi: 10.1136/gut.2004.046516

See end of article for authors' affiliations

Correspondence to:

Dr T Kiyohara, Department of Internal Medicine and

Molecular Science,

Graduate School of

Medicine, Osaka

University, 2-2 B-5

Yamadaoka, Suita, 565-

0871, Japan; kiyohara@

imed2.med.osaka-u.ac.jp

Revised version received 28 October 2004

Accepted for publication

1 November 2004
Background and aims: A characteristic feature of Crohn's disease (CD) is mesenteric adipose tissue hypertrophy. Mesenteric adipocytes or specific proteins secreted by them may play a role in the pathogenesis of CD. We recently identified adiponectin as an adipocyte specific protein with antiinflammatory properties. Here we report on expression of adiponectin in mesenteric adipose tissue of CD patients.

Methods and results: Mesenteric adipose tissue specimens were obtained from patients with $C D(n=22)$, ulcerative colitis (UC) $(n=8)$ and, for controls, colon carcinoma patients $(n=28)$ who underwent intestinal resection. Adiponectin concentrations were determined by enzyme linked immunosorbent assay, and adiponectin mRNA levels were determined by real time quantitative reverse transcription-polymerase chain reaction. Tissue concentrations and release of adiponectin were significantly increased in hypertrophied mesenteric adipose tissue of CD patients compared with normal mesenteric adipose tissue of $C D$ patients $(p=0.002, p=0.040$, respectively), $U C$ patients $(p=0.002, p=0.003)$, and controls $(p<0.0001, p<0.0001)$. Adiponectin mRNA levels were significantly higher in hypertrophied mesenteric adipose tissue of CD patients than in paired normal mesenteric adipose tissue from the same subjects $(p=0.024)$. Adiponectin concentrations in hypertrophied mesenteric adipose tissue of CD patients with an internal fistula were significantly lower than those of $C D$ patients without an internal fistula $(p=0.003)$. Conclusions: Our results suggest that adipocytes in hypertrophied mesenteric adipose tissue produce and secrete significant amounts of adiponectin, which could be involved in the regulation of intestinal inflammation associated with CD. ing a short non-collagenous $\mathrm{N}$ terminal segment followed by a collagen-like sequence. It belongs to the family of proteins that include $\mathrm{Clq}$ and the collectins, ${ }^{67}$ which play important roles in the innate humoral immune system. ${ }^{8-10}$ We and others have shown that adiponectin modulates a wide array of biological functions. Adiponectin was demonstrated to be related to improved insulin resistance and prevention of atherosclerosis, fatty liver, and liver fibrosis. ${ }^{11-19}$ In addition to the above actions, we reported that adiponectin has several anti-inflammatory effects. For example, adiponectin reduces monocyte attachment to cultured human aortic endothelial cells by inhibiting expression of vascular cell adhesion molecules, intercellular adhesion molecules, and E-selectin. ${ }^{20}$ Adiponectin inhibits the phagocytic activity and production of tumour necrosis factor (TNF)- $\alpha$ and interleukin (IL)-6 in cultured macrophages. ${ }^{721}$ These actions may be mediated by suppression of nuclear factor $\kappa \mathrm{B}$ signalling and extracellular signal regulated kinase 1/2 activity. ${ }^{21}{ }^{22}$ Adiponectin knockout mice display high levels of TNF- $\alpha$ mRNA in adipose tissue and high concentrations in plasma, which decrease by supplementation of plasma adiponectin. ${ }^{12}$ Furthermore, we recently reported that adiponectin enhances the production of IL-10 and tissue inhibitor of metalloproteinase 1 in human cultured macrophages. ${ }^{23}$ Thus adiponectin exhibits antiinflammatory properties, especially in endothelial cells and macrophages.

To our knowledge, the role of adiponectin in the pathogenesis of $\mathrm{CD}$ has not been examined previously. The present study was designed to determine expression levels of adiponectin in hypertrophied mesenteric adipose tissue, and its relevance to the pathogenesis of $\mathrm{CD}$.

Abbreviations: $C D$, Crohn's disease; UC, ulcerative colitis; TNF- $\alpha$, tumour necrosis factor- $\alpha$; IL, interleukin; BMI, body mass index; ELISA, enzyme linked immunosorbent assay; RT-PCR, reverse transcriptionpolymerase chain reaction; CDNA, complementary DNA; CRP, C reactive protein; PPAR $\gamma$, peroxisome proliferator activated receptor $\gamma$ 


\section{MATERIALS AND METHODS}

\section{Patients and specimen preparation}

The study protocol was approved by the Human Ethics Review Committee of Osaka University School of Medicine and a signed consent form was obtained from each subject. Mesenteric adipose tissue specimens were obtained from 22 patients with CD, eight with ulcerative colitis (UC), and 28 with colon cancer who underwent surgical resection. CD patients (16 men, six women; mean age 34.4 (1.8) years (range 24-56); mean body mass index (BMI) $18.8(0.4) \mathrm{kg} / \mathrm{m}^{2}$ ) underwent ileal or colonic resection because of stenosis or an internal fistula. Three patients with $\mathrm{CD}$ were treated by steroids. The other patients were not on any specific medical treatment at the time of the study. Eleven patients with CD had pure ileal involvement, 10 had ileocolonic CD, and one had colonic CD. Ten patients with $C D$ had an internal fistula. UC patients (five men, three women; mean age 49.4 (5.2) years (range 32-69); mean BMI 21.4 (0.8) kg/m²) underwent intestinal resection because of steroid dependency or lack of response to medication. Patients with colon cancer (19 men, nine women; mean age 67.3 (1.3) years (range 53-75); mean BMI $22.4(0.6) \mathrm{kg} / \mathrm{m}^{2}$ ) were enrolled as the control group. All specimens were taken from mesenteric adipose tissue close to the intestinal wall. In 16 of 22 CD patients, paired samples were obtained from hypertrophied mesenteric adipose tissue adjacent to the involved intestine and apparently normal mesenteric adipose tissue contiguous with the healthy segment of the intestine. Resected specimens were immediately frozen in liquid nitrogen and stored $-80^{\circ} \mathrm{C}$ until assayed. Some samples were fixed in $10 \%$ phosphate buffered formalin and embedded in paraffin for histopathological studies.

\section{Histopathological analysis}

Haematoxylin and eosin staining was routinely performed. For quantitation of the size and number of adipocytes, sectional areas of adipose tissue were analysed with an image analysis system (Macscope version 2.59; Mitani, Fukui, Japan). Tissue samples were immunohistologically stained for CD3, CD20, and CD68 using the labelled streptavidinbiotin system (Dako, Glostrup, Denmark). Mouse monoclonal antihuman CD68, CD3, and CD20 antibodies were purchased from Nichirei (Tokyo, Japan). For immunohistological staining of adiponectin, paraffin sections were deparaffinised, dehydrated, blocked with normal goat serum (Vector Laboratories, Burlingame, California, USA) for 10 minutes at room temperature, and then incubated at $4^{\circ} \mathrm{C}$ overnight with $5 \mu \mathrm{g} / \mathrm{ml}$ of a mouse monoclonal antihuman adiponectin antibody, ANOC 9104. ${ }^{22}$ Sections were then rinsed with $0.05 \mathrm{M}$ Tris $\mathrm{HCl}$ buffer ( $\mathrm{pH} 7.6$ ), and incubated for 30 minutes with a 1:200 dilution of Alexa Fluor 594 goat antimouse IgG $(\mathrm{H}+\mathrm{L})$ (Molecular Probes, Eugene, Oregon, USA) at room temperature. As a negative control, the primary antibody was replaced by normal mouse serum (Dako). Nuclear counterstaining was carried out with a 1:5000 dilution of 4', 6-diamidino-2-phenylindole (Molecular Probes) for five minutes at room temperature.

\section{Determination of adiponectin and IL- 6 concentrations in mesenteric adipose tissue}

Mesenteric adipose tissue samples were homogenised in lysis buffer containing $20 \mathrm{mM}$ Tris ( $\mathrm{pH} 8.0$ ), $137 \mathrm{mM} \mathrm{NaCl}, 10 \%$ glycerol, 1\% Nonidet P-40, $10 \mathrm{mM}$ ethylenediaminetetra acetic acid, $100 \mathrm{mM} \mathrm{NaF}, 1 \mathrm{mM}$ phenylmethylsulfonylfluoride, $0.25 \mathrm{TIU} / \mathrm{ml}$ aprotinin, and $10 \mu \mathrm{g} / \mathrm{ml}$ leupeptin. Homogenates were incubated for 10 minutes at $4^{\circ} \mathrm{C}$ and then centrifuged at $16000 \mathrm{~g}$ for 15 minutes at $4^{\circ} \mathrm{C}$. The supernatants were collected and stored at $-30^{\circ} \mathrm{C}$ until assayed. Adiponectin concentrations in homogenate supernatants of adipose tissues were determined by enzyme linked immunosorbent assay (ELISA), as described previously. ${ }^{24}$ IL-6 concentrations were measured using ELISA kits (BioSource International, Camarillo, California, USA). Total protein concentration was then determined using BCA Protein Assay Reagent (Pierce, Rockford, Illinois, USA) according to the manufacturer's instructions. The final concentrations were expressed in ng of adiponectin and pg of IL-6 per mg of total protein.

\section{Adiponectin release in short term cultures}

Short term cultures were prepared with surgical specimens to examine release of adiponectin from the mesenteric adipose tissue. Adipose tissue samples (250 mg, wet weight) were diced finely and incubated in $2 \mathrm{ml}$ of culture medium at $37^{\circ} \mathrm{C}$ in a $95 \% \mathrm{O}_{2}-5 \% \mathrm{CO}_{2}$ humidified incubator for 24 hours, as described previously..$^{25}$ Conditioned media were collected and stored at $-30^{\circ} \mathrm{C}$ until used for assay. Adiponectin concentrations in conditioned media were then determined by ELISA.

\section{Quantitation of adiponectin mRNA in mesenteric adipose tissue}

Total RNA was extracted and reverse transcribed into complementary DNA (cDNA) as described previously. ${ }^{24}$ Real time quantitative polymerase chain reaction (PCR) was carried out on cDNA as described previously. ${ }^{14}$ The sequences of the primers and the probe for adiponectin were as follows: adiponectin sense primer, 5' -AGG TTG GAT GGC GGG C-3'; adiponectin antisense primer, $5^{\prime}$-TTT CAC CGA TGT CTC CCT TAG G-3'; adiponectin probe, 5' -(FAM)-TGG CAG AGA TGG CAC CCC TGG-(TAMRA)-3'. The primers and probe for $\beta$-actin were purchased from Applied Biosystems (Foster City, California, USA). The quantity of adiponectin was expressed as the ratio of adiponectin cDNA molecules to $\beta$-actin cDNA molecules.

\section{Statistical analysis}

Data are expressed as mean (SEM). Differences among the four groups were studied using the Kruskal-Wallis test for global comparisons and the Mann-Whitney test for paired comparisons. Paired and unpaired $t$ tests were used to compare data between two groups when they showed normal distribution and the Mann-Whitney test when they were asymmetrical. Spearman's test was applied to test for correlations. A p value $<0.05$ denoted the presence of a statistically significant difference.

\section{RESULTS \\ Analysis of inflammatory cells and adipocytes in mesenteric adipose tissue}

Histopathological examination showed a large number of inflammatory cells in hypertrophied mesenteric adipose tissue adjacent to the involved intestine of $\mathrm{CD}$ patients (fig 1B). In contrast, very few inflammatory cells were detected in normal mesenteric adipose tissue adjacent to the healthy intestine of $\mathrm{CD}$ patients, the intestines of UC patients, and the intestines of control subjects (fig lA). Immunohistochemical staining using mouse monoclonal antibodies to CD68, CD3, and CD20 showed many CD68 positive (specific for monocytes/macrophages), CD3 positive (specific for T cells), and CD20 positive (specific for B cells) cells near the serosa in hypertrophied mesenteric adipose tissue of CD patients (fig $\mathrm{lC}-\mathrm{E}$ ). The number of inflammatory cells decreased with increased distance from the serosa. The number of CD20 positive cells appeared to be less than other inflammatory cells. Quantitative analyses indicated that the size of adipocytes in hypertrophied mesenteric adipose tissue of CD patients $\left(956(21) \mu^{2}\right.$ ) was approximately one quarter the size of those in mesenteric adipose tissue from 


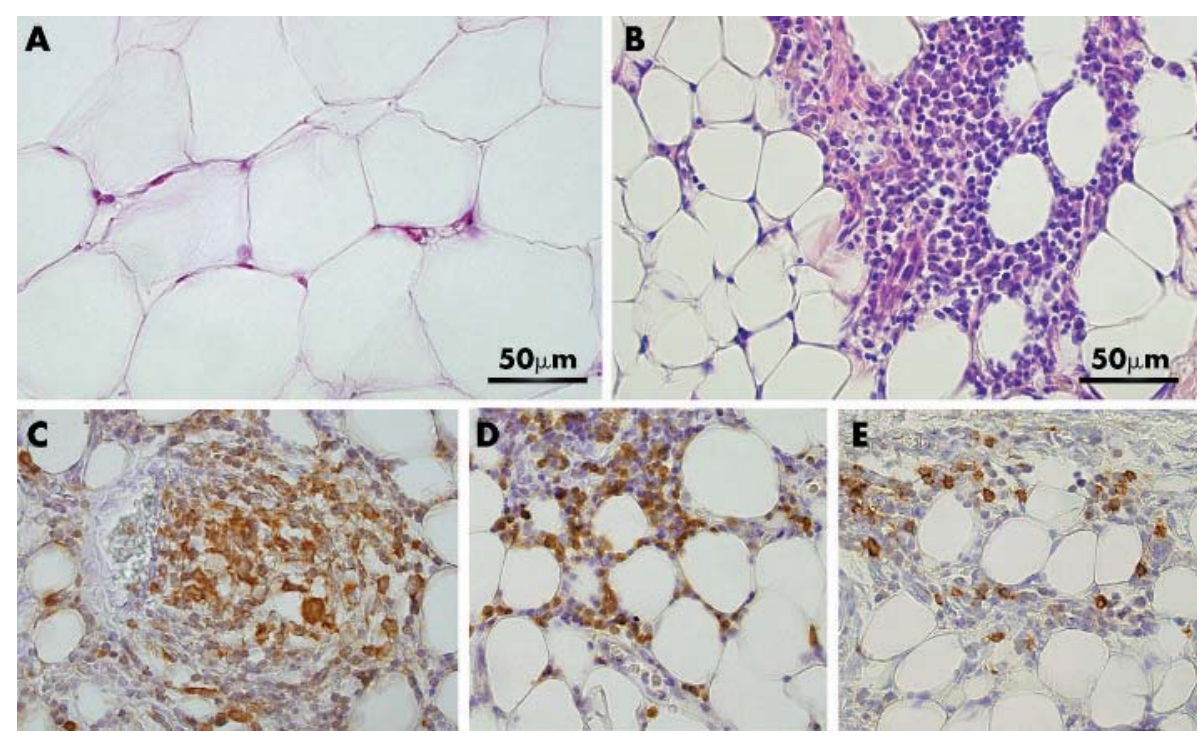

Figure 1 Haematoxylin-eosin (H\&E) staining and immunohistochemical detection of CD68, CD3, and CD20 in hypertrophied mesenteric adipose tissue contiguous with involved intestinal segments of a representative patient with Crohn's disease (CD). Mesenteric adipose tissue in a normal control subject (A) and hypertrophied mesenteric adipose tissue of a CD patient (B) were stained with H\&E. Note that the size of adipocytes in hypertrophied mesenteric adipose tissue is approximately one quarter those of controls (A, B). CD68, CD3, and CD20 expressing cells were stained dark brown (C-E). Many CD68, CD3, and CD20 positive cells were present near the serosa in hypertrophied mesenteric adipose tissue. CD68 positive cells formed a non-caseous epithelioid cell granuloma (C). Nuclear counterstaining: Mayer's haematoxylin. Original magnification $\times 200$.

controls (4099 (174) $\mu \mathrm{m}^{2}$ ) (fig 1B, A). On the other hand, the number of adipocytes per unit area in hypertrophied mesenteric adipose tissue of CD patients was 3.5-fold that of adipocytes in the mesenteric adipose tissue from controls (603 $v 173$ per $\left.900000 \mu \mathrm{m}^{2}\right)$.

\section{Immunostaining of adiponectin in mesenteric adipose tissue}

Adiponectin immunoreactivity appeared as a red fluorescence rim at the periphery of the cytoplasm of adipocytes in the mesenteric adipose tissue of controls and CD patients (fig 2B,
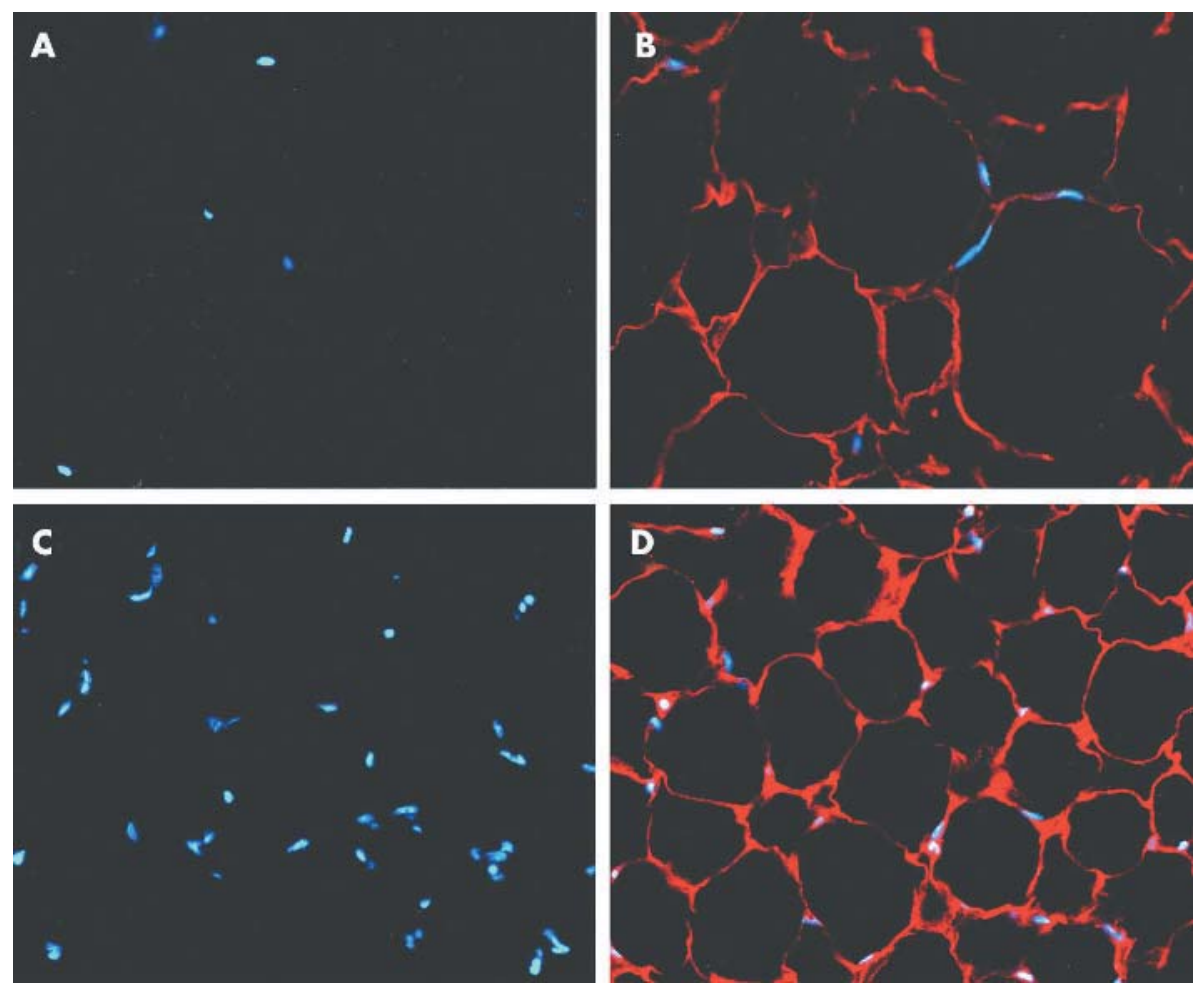

Figure 2 Immunohistochemical staining of adiponectin in the mesenteric adipose tissue of a representative control and Crohn's disease (CD) patient. The mesenteric adipose tissue of the control (B) and the hypertrophied mesenteric adipose tissue of a CD patient (D) reacted with antiadiponectin antibody. No reaction product was detected against non-immune serum in the mesenteric adipose tissue of the control (A) and hypertrophied mesenteric adipose tissue of the CD patient $(C)$. Adiponectin staining appeared as a red fluorescence rim in the periphery of the cytoplasm of adipocytes (B, D). Nuclear counterstaining: 4', 6-diamidino-2-phenylindole. Original magnification: $\times 200$. 

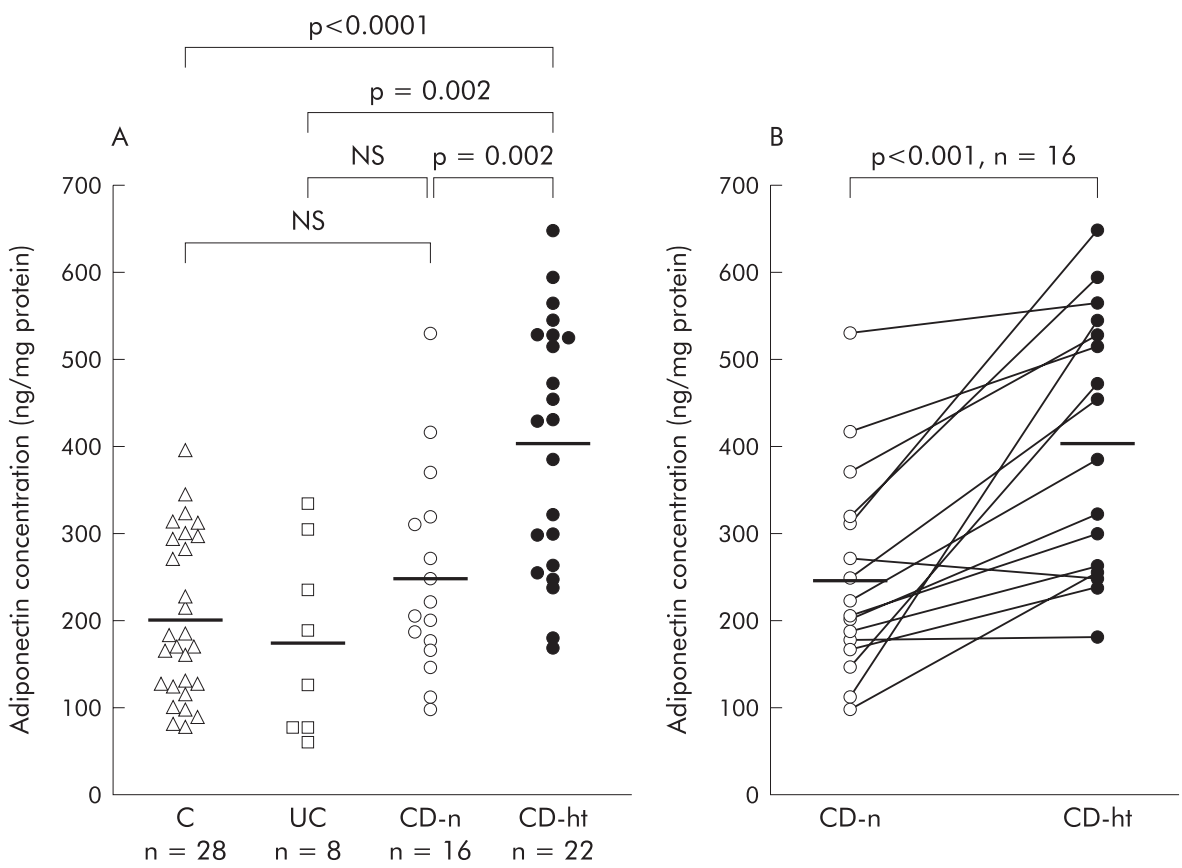

Figure 3 Adiponectin concentrations in mesenteric adipose tissue. Adiponectin concentrations were determined by enzyme linked immunosorbent assay (ELISA) and values expressed in $\mathrm{ng}$ of adiponectin per $\mathrm{mg}$ of total homogenate protein. (A) Data are individual and mean values (horizontal bar) of adiponectin concentrations in normal mesenteric adipose tissues of controls (C), ulcerative colitis patients (UC), Crohn's disease patients (CD-n), and hypertrophied mesenteric adipose tissues of CD patients (CD-ht). (B) Data are individual and mean values (horizontal bars) of adiponectin concentrations in normal mesenteric adipose tissues of CD patients (CD-n) and hypertrophied mesenteric adipose tissues of CD patients (CD-ht) from the same patients.

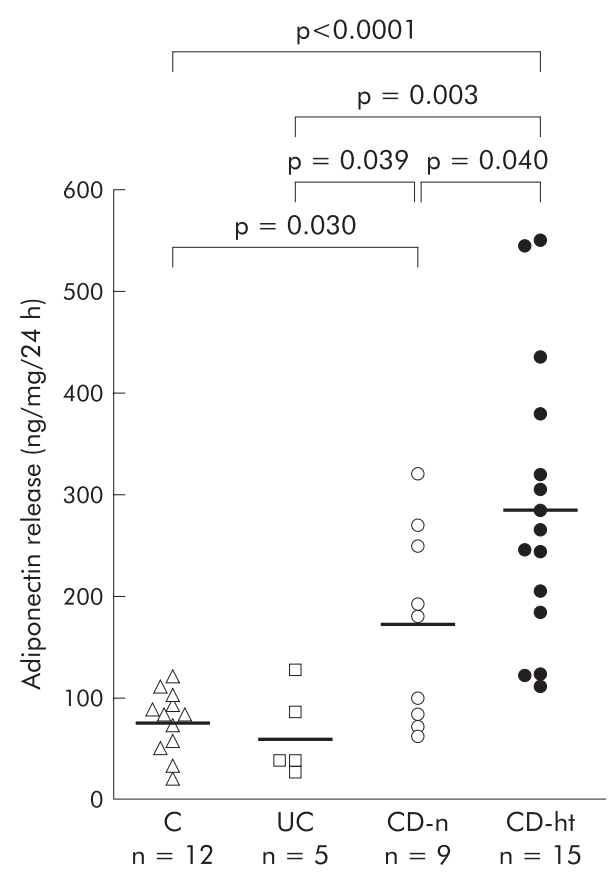

Figure 4 Adiponectin release from the mesenteric adipose tissue in short term culture. Release of adiponectin from adipose tissue was determined by enzyme linked immunosorbent assay and values expressed in $\mathrm{ng}$ of adiponectin per $\mathrm{ml}$ of conditioned media. Data are individual and mean values (horizontal bars) of adiponectin release from normal mesenteric adipose tissues of controls (C), ulcerative colitis patients (UC), Crohn's disease patients (CD-n), and hypertrophied mesenteric adipose tissues of CD patients (CD-ht).
D). In addition, sections incubated with normal mouse serum instead of mouse antihuman adiponectin antibody (fig 2A, C) or mouse antihuman adiponectin antibody preabsorbed with sufficient adiponectin showed no positive staining reaction (data not shown).

\section{Adiponectin concentration in mesenteric adipose tissue}

The mean adiponectin concentration in hypertrophied mesenteric adipose tissue of CD patients (404.7 (31.9) ng/mg) was significantly higher than that in normal mesenteric adipose tissue of controls (202.5 (17.7) ng/mg, p<0.0001), UC patients (176.1 (37.9) ng/mg, p =0.002), or CD patients (249.3 (29.1) ng/mg, $p=0.002$ ) (fig 3A). Moreover, adiponectin concentrations in hypertrophied mesenteric adipose tissues (407.4 (37.5) ng/mg) were also significantly higher than those in paired normal mesenteric adipose tissues (249.3 (29.1) ng/ $\mathrm{mg}$ ) from the same CD patients $(\mathrm{p}<0.001)$ (fig $3 \mathrm{~B})$.

\section{Adiponectin release from mesenteric adipose tissue} The amount of adiponectin released from hypertrophied mesenteric adipose tissue of CD patients $(287.9$ (36.0) ng/ml) was significantly higher than that from normal mesenteric adipose tissue of controls (76.0 (8.9) ng/ml, p $<0.0001$ ), UC patients $(63.4(19.0) \mathrm{ng} / \mathrm{ml}, \mathrm{p}=0.003)$, or CD patients $(170.2$ (31.9) $\mathrm{ng} / \mathrm{ml}, \mathrm{p}=0.040$ ) (fig 4). Furthermore, adiponectin release from normal mesenteric adipose tissue of $\mathrm{CD}$ patients was significantly higher than that from the mesenteric adipose tissue of control subjects $(\mathrm{p}=0.030)$ or UC patients $(\mathrm{p}=0.039)($ fig 4$)$.

\section{Adiponectin mRNA expression in the mesenteric adipose tissue of $C D$ patients}

Quantitative real time reverse transcription (RT)-PCR showed a significantly higher expression level of adiponectin mRNA 


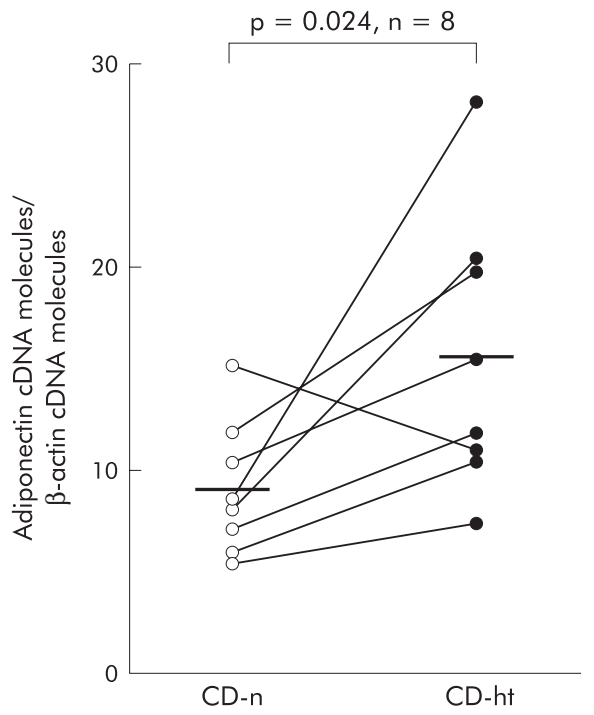

Figure 5 Quantitative real time reverse transcription-polymerase chain reaction analysis of adiponectin mRNA expression in mesenteric adipose tissue. Data are individual and mean values (horizontal bars) of adiponectin CDNA molecules per molecule of $\beta$-actin CDNA in normal mesenteric adipose tissues of Crohn's disease patients (CD-n) and hypertrophied mesenteric adipose tissues of CD patients (CD-ht) from the same patients.

in hypertrophied mesenteric adipose tissue of $\mathrm{CD}$ patients $\left(15.1 \times 10^{-2}\left(2.1 \times 10^{-2}\right)\right.$ cDNA molecules) compared with that in paired normal mesenteric adipose tissue $\left(8.9 \times 10^{-2}\right.$ $\left(1.1 \times 10^{-2}\right)$ cDNA molecules) $(\mathrm{p}=0.024)($ fig 5$)$.
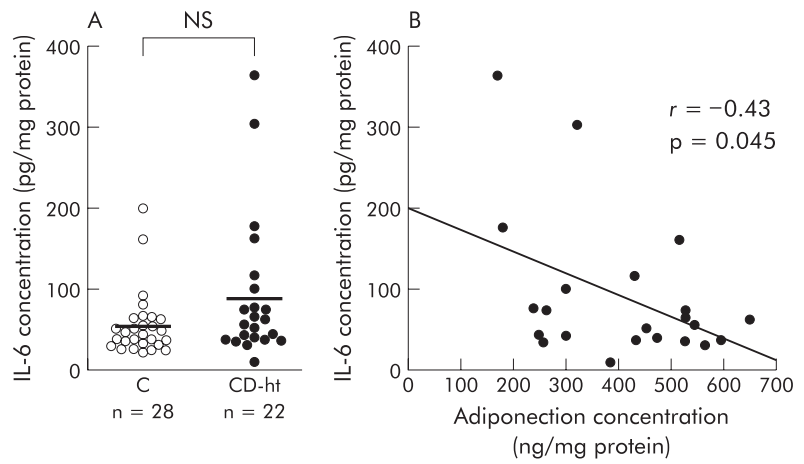

Figure 7 (A) Interleukin 6 (IL-6) concentrations in the mesenteric adipose tissue of controls (C) and hypertrophied mesenteric adipose tissue of Crohn's disease patients (CD-ht). IL-6 concentrations were determined by enzyme linked immunosorbent assay and values expressed in pg of IL-6 per mg of total homogenate protein. (B) Correlation between adiponectin and IL- 6 concentrations in hypertrophied mesenteric adipose tissue of CD patients.

\section{Correlation between adiponectin concentrations in hypertrophied mesenteric adipose tissue and laboratory data of CD patients}

We next evaluated the relationship between adiponectin concentrations in hypertrophied mesenteric adipose tissue and laboratory data measured just prior to surgery in CD patients. There was no significant correlation between adiponectin concentrations in hypertrophied mesenteric adipose tissues and leucocyte count, haemoglobin level, or platelet count in CD patients $(r=-0.13, \mathrm{p}=0.558 ; r=-0.15$, $\mathrm{p}=0.507 ; r=-0.18, \mathrm{p}=0.434$, respectively) (fig $6 \mathrm{~A}-\mathrm{C}$ ). On the other hand, adiponectin concentrations in hypertrophied mesenteric adipose tissues of CD patients correlated inversely
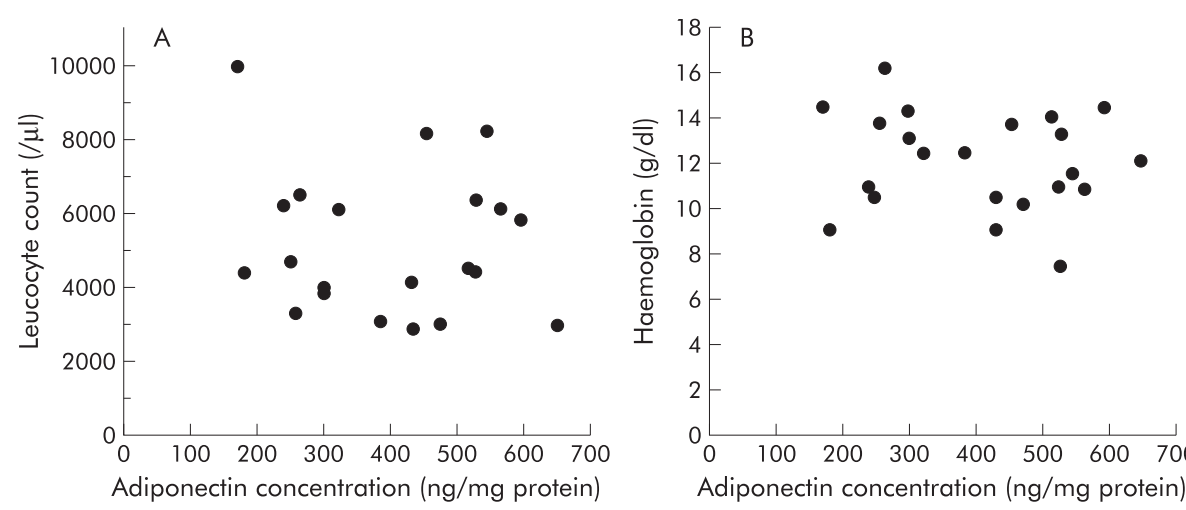

Figure 6 Correlation between adiponectin concentrations in hypertrophied mesenteric adipose tissue of Crohn's disease patients and leucocyte count (A), haemoglobin level (B), platelet count (C), and serum $C$ reactive protein (CRP) levels (D). These laboratory data were determined just prior to surgery.
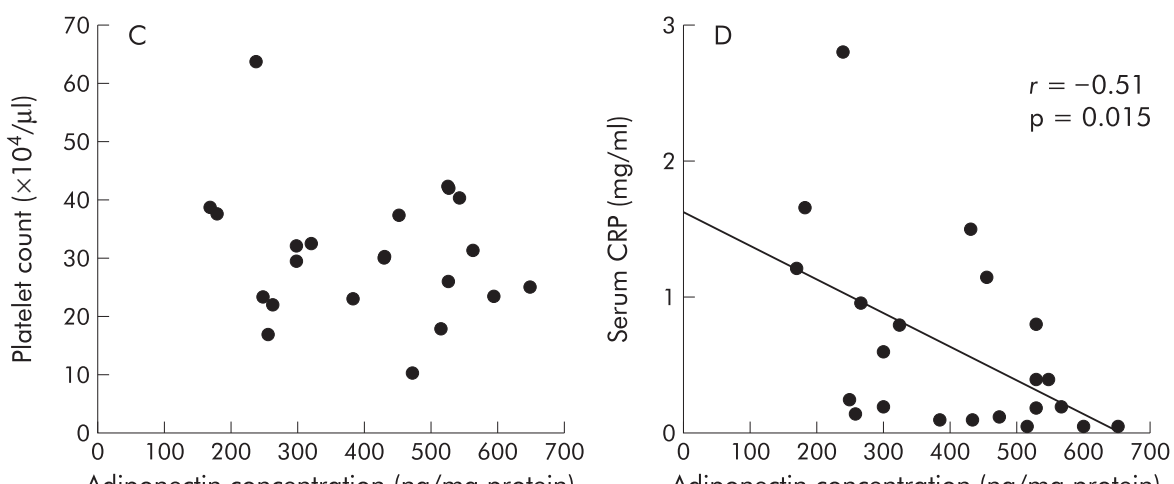

Adiponectin concentration ( $\mathrm{ng} / \mathrm{mg}$ protein) 
with serum C reactive protein (CRP) levels $(r=-0.51$, $\mathrm{p}=0.015$ ) (fig 6D). There was no significant correlation between tissue adiponectin concentrations and serum CRP levels in control subjects or UC patients $(r=-0.32, \mathrm{p}=0.097$ and $r=-0.37, \mathrm{p}=0.369$, respectively).

\section{Relationship between adiponectin and IL- 6 concentrations in hypertrophied mesenteric adipose tissue of $C D$ patients}

Based on the above finding, we evaluated the relationship between adiponectin and the proinflammatory cytokine IL-6, a major inducer of CRP. The concentration of IL- 6 in hypertrophied mesenteric adipose tissues of $\mathrm{CD}$ patients (90.3 (19.1) $\mathrm{pg} / \mathrm{mg}$ ) tended to be higher than that in the mesenteric adipose tissues of control subjects (54.4 (7.6) pg/ $\mathrm{mg})$ but the difference was not statistically significant $(p=0.063)$ (fig 7A). In hypertrophied mesenteric adipose tissue of CD patients, IL-6 concentrations correlated inversely with adiponectin concentrations $(r=-0.43, \mathrm{p}=0.045)$ (fig 7B).

\section{Adiponectin concentrations in the mesenteric adipose tissue of $C D$ patients with or without internal fistula} To investigate the association of adiponectin production in mesenteric adipose tissue with the development of an internal fistula, we examined adiponectin concentrations in the mesenteric adipose tissues of CD patients with an internal fistula (eight men, two women; mean age 32.1 (1.9) years (range 24-43)) and without an internal fistula (eight men, four women; mean age 36.3 (2.9) years (range 25-56)). These two groups were matched for age, BMI (18.4 (0.8) $v$ $19.0(0.4) \mathrm{kg} / \mathrm{m}^{2}$ ), and disease duration (5.8 (1.7) $v 7.5$ (1.4) years). Adiponectin concentrations in hypertrophied mesenteric adipose tissues of CD patients with a fistula (312.4 (37.3) ng/mg) were significantly lower than those without a fistula (481.6 (34.2) ng/mg, p=0.003) (fig 8). Furthermore, adiponectin concentrations in normal mesenteric adipose tissues of CD patients with a fistula (234.5 (28.8) ng/mg) also tended to be lower than those without a

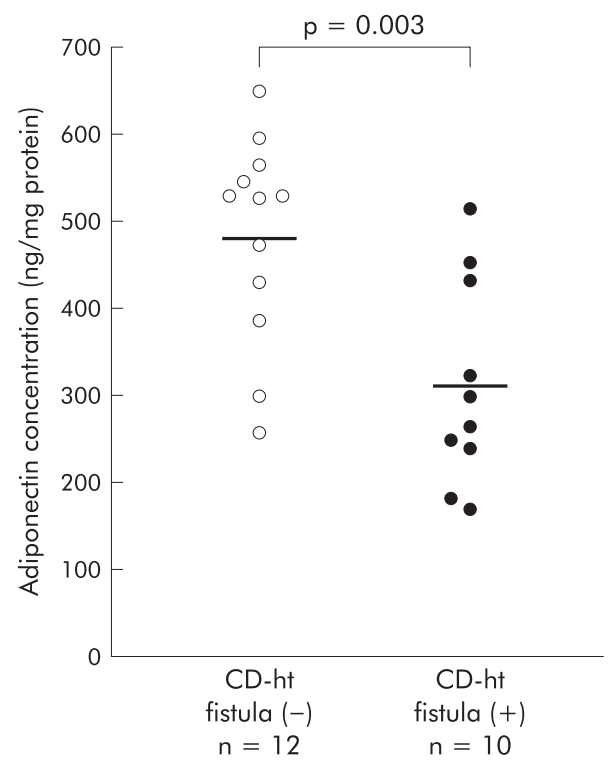

Figure 8 Adiponectin concentrations in hypertrophied mesenteric adipose tissue of Crohn's disease (CD) patients with or without internal fistula. Data are individual and mean values (horizontal bars) of adiponectin concentrations in hypertrophied mesenteric adipose tissues of CD patients without an internal fistula (CD-ht fistula (-)) and those of CD patients with an internal fistula (CD-ht fistula $(+))$. fistula (264.0 (52.4) ng/mg) although the difference was not statistically significant $(\mathrm{p}=0.629)$.

\section{Correlation between BMI and adiponectin concentrations or its release}

Finally, we evaluated the correlation between BMI and adiponectin concentrations or its release. Adiponectin concentrations and the amount released in all specimens correlated inversely with BMI $(r=-0.40, \mathrm{p}<0.001$ and $r=-0.52, \mathrm{p}<0.001$, respectively) (fig 9A, B). However, there was no significant correlation between BMI and adiponectin concentration or its release in each subgroup; normal mesenteric adipose tissue of controls $(r=-0.32, \mathrm{p}=0.099$ and $r=-0.31, \mathrm{p}=0.328$, respectively), UC patients $(r=$ $-0.62, \mathrm{p}=0.102$ and $r=-0.25, \mathrm{p}=0.682$, respectively), and CD patients $(r=-0.13, \mathrm{p}=0.619$ and $r=-0.38, \mathrm{p}=0.318$, respectively) and hypertrophied mesenteric adipose tissue of CD patients $(r=-0.02, \mathrm{p}=0.934$ and $r=-0.25, \mathrm{p}=0.378$, respectively).

\section{DISCUSSION}

The presence of hypertrophied mesenteric adipose tissue is one of the characteristic features of $\mathrm{CD} .{ }^{1}$ This change is important in terms of surgery for $\mathrm{CD}$, and its recognition is crucial in determining the extent of resection and, from another point of view, in differentiating CD from other bowel diseases. ${ }^{4}$ Although the mesenteric fat hypertrophy in CD has long been recognised, its significance remains unknown. Adiponectin, an adipocyte specific secretory protein, was recently shown to play a role in the modulation of a wide array of biological functions. Recent studies have shown that adiponectin has anti-inflammatory effects, especially in endothelial cells and macrophages. ${ }^{70-24}$ Thus its secretion by mesenteric adipocytes could negatively regulate some of the inflammatory reactions observed in CD. The present study demonstrated for the first time that adiponectin production is enhanced in hypertrophied mesenteric adipose tissue contiguous with the involved intestine of CD patients.

Only a few histopathological studies of the mesenteric adipose tissue in CD have been reported. Fibrosis, perivascular inflammation, and intimal and medial thickening of vessels have been observed in hypertrophied mesenteric adipose tissue adjacent to the involved intestine of $\mathrm{CD}$ patients. ${ }^{26}{ }^{27}$ In the present study, two additional histopathological features of hypertrophied mesenteric adipose tissue of CD patients were defined: significant infiltration of inflammatory cells and reduced size of adipocytes. Infiltrated cells were mainly CD68 positive and CD3 positive T lymphocytes. Massive infiltration of CD68 positive and CD3 positive cells suggests that the inflamed mucosa and its adjacent mesentery share a common inflammation in CD. These cells may disturb mesenteric functions, including blood and lymphatic flow, and hence contribute to mucosal damage. They may also interact with mesenteric adipocytes and induce hyperplasia. The morphological change in adipocytes is more interesting. As small adipocytes are capable of producing larger amounts of adiponectin compared with large adipocytes $^{28}$ the reduced size of adipocytes in hypertrophied mesenteric adipose tissue of CD patients is consistent with the increase in adiponectin production reported herein. Desreumaux and colleagues $^{29}$ found significantly high expression levels of peroxisome proliferator activated receptor $\gamma($ PPAR $\gamma)$ mRNA in hypertrophied mesenteric adipose tissue of $\mathrm{CD}$ patients compared with normal mesenteric adipose tissue of $\mathrm{CD}$ patients and control subjects. PPAR $\gamma$ is a member of the nuclear hormone receptor superfamily, which is predominantly expressed in adipocytes. ${ }^{30}{ }^{31}$ PPAR $\gamma$ is a key regulator of adipogenesis. As activation of PPAR $\gamma$ leads to an increase in small adipocytes and upregulates their expression 

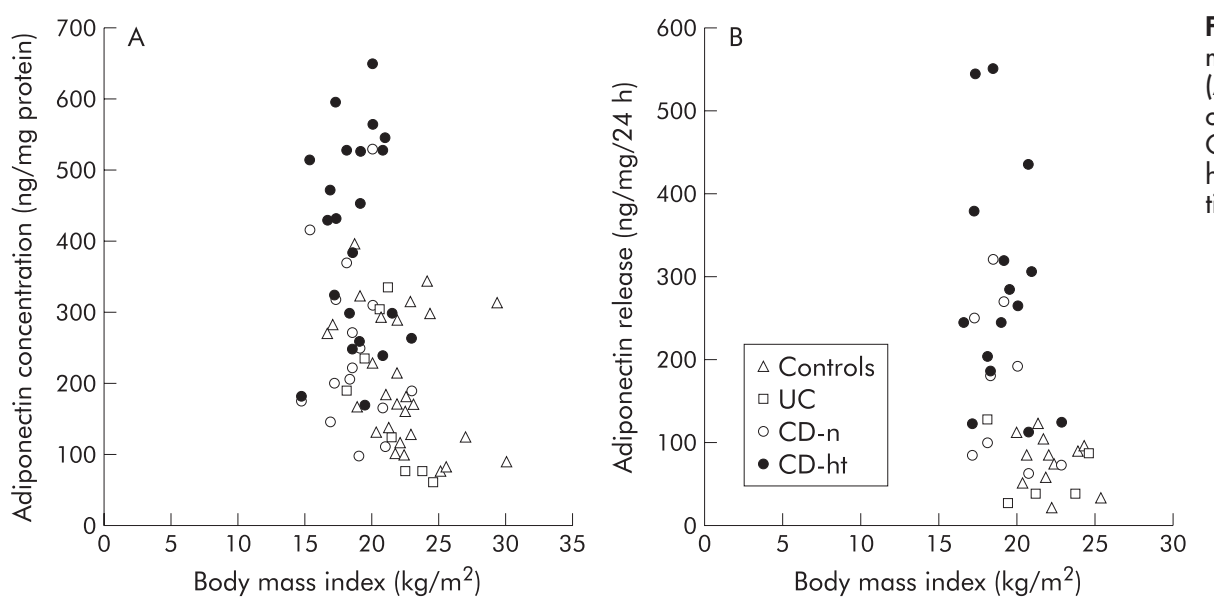

Figure 9 Relationship between body mass index and tissue concentrations (A) or release (B) of adiponectin in controls, ulcerative colitis patients (UC), Crohn's disease patients (CD-n), and hypertrophied mesenteric adipose tissue of $C D$ patients (CD-ht).

of adiponectin, ${ }^{2832-34}$ our results may be relevant to overexpression of PPAR $\gamma$. Infiltrated cells are a possible source of PPAR $\gamma$ ligands such as 15 -deoxy- $\Delta^{12-14}$-prostaglandin $\mathrm{J}_{2} \cdot{ }^{35-37}$

A negative relationship between BMI and plasma adiponectin levels has been reported..$^{38}$ In the present study, adiponectin concentrations and its release in all specimens of mesenteric adipose tissues correlated inversely with BMI. The high adiponectin concentration and release in CD patients may be partly explained by the lower BMI compared with controls and UC patients. However, in the paired samples of CD patients, adiponectin concentrations and mRNA levels in hypertrophied mesenteric adipose tissues were significantly higher than in normal mesenteric adipose tissues. Furthermore, adiponectin concentration and release in hypertrophied mesenteric adipose tissue of CD patients were shifted upwards in the scattered plot diagrams with BMI compared with the other subgroups (fig 9A, B). These results suggest that increased adiponectin production in hypertrophied mesenteric adipose tissue of $\mathrm{CD}$ patients is not only attributed to the lower BMI but also to other factors, including PPAR $\gamma$ ligands, as discussed above.

In the present study, adiponectin concentrations in hypertrophied mesenteric adipose tissue of CD patients correlated negatively with serum CRP levels. However, this inverse correlation was not significant in UC patients and controls. While the exact link between tissue adiponectin concentration and serum CRP level is not clear at present, this difference may be relevant to the characteristic involvement of mesenteric adipose tissue in the pathogenesis of CD. On the other hand, our study also demonstrated a negative correlation between adiponectin and IL-6 production in hypertrophied mesenteric adipose tissue of $C D$ patients. This finding suggests that adiponectin inhibits inflammatory cytokine production in mesenteric adipose tissue. As IL-6 is a major inducer of CRP, ${ }^{39}{ }^{40}$ it may be the missing link between adiponectin and CRP.

In $\mathrm{CD}$, internal fistulas develop almost exclusively at the mesenteric border. Our results showed significantly low adiponectin concentrations in hypertrophied mesenteric adipose tissues of $\mathrm{CD}$ patients with an internal fistula compared with those free of this complication. Such a decrease in adiponectin production may worsen the inflammation and increase the risk of internal fistula formation. As anti-TNF- $\alpha$ therapy (infliximab) is effective in the treatment of internal fistulas in $\mathrm{CD}$, this result may have relevance to the anti-TNF- $\alpha$ effects of adiponectin. ${ }^{7221}$ The exact mechanisms that cause reduction of adiponectin concentrations in hypertrophied mesenteric adipose tissue of CD patients with a fistula remain elusive and further studies are needed to identify these mechanisms.

Adipocytes produce several adipocytokines, including proinflammatory cytokines. It has been reported that TNF- $\alpha$ mRNA levels in hypertrophied mesenteric adipose tissue of CD patients tended to be higher than in normal mesenteric adipose tissue of $\mathrm{CD}$ patients but the difference between these locations was not statistically significant. ${ }^{29}$ While mesenteric adipocytes may produce both TNF- $\alpha$ and adiponectin, our results suggest that the latter is a significant adipocytokine derived from mesenteric adipocytes stimulated by transmural inflammation as a result of CD. Barbier and colleagues $^{41}$ recently reported high mRNA levels of leptin in the mesenteric adipose tissue of patients with CD and UC. However, leptin levels in hypertrophied mesenteric adipose tissue of $C D$ patients were lower than those in normal mesenteric adipose tissue of CD patients, and similar to those in the mesenteric adipose tissue of UC patients. ${ }^{41}$ Considered together, it is conceivable that the mechanisms that regulate leptin production are different to those of adiponectin and TNF- $\alpha$.

In conclusion, we have demonstrated in the present study that adipocytes in hypertrophied mesenteric adipose tissue of CD patients produce and secrete significant amounts of adiponectin. Mesenteric adipocytes may act, not only as energy storage cells, but also as immunoregulating cells in the case of intestinal inflammation via adiponectin production. The hypertrophied mesenteric adipose tissue of $C D$ patients could serve as a barrier that prevents the spread of inflammation into the intra-abdominal space. Dysregulation of adiponectin production in mesenteric adipose tissue may play a role in the pathogenesis of intestinal disorders, including CD.

\section{ACKNOWLEDGEMENTS}

We gratefully acknowledge the technical assistance of Sachiyo Tanaka and Fumie Katsube.

\section{Authors' affiliations}

K Yamamoto, T Kiyohara, Y Murayama, S Kihara, Y Okamoto, T Funahashi, S Tsutsui, J-I Miyagawa, S Tamura, I Shimomura, Y Shinomura, Department of Internal Medicine and Molecular Science, Graduate School of Medicine, Osaka University, Osaka, Japan T Ito, Department of Surgery, Graduate School of Medicine, Osaka University, Osaka, Japan

R Nezu, Department of Surgery, Osaka Rosai Hospital, Osaka, Japan Y Matsuzawa, Department of Internal Medicine, Sumitomo Hospital, Osaka, Japan

Conflict of interest: None declared. 


\section{REFERENCES}

1 Sheehan AL, Warren BF, Gear MW, et al. Fat-wrapping in Crohn's disease: pathological basis and relevance to surgical practice. Br J Surg 1992; 79:955-8

2 Smedh K, Olaison G, Nystrom PO, et al. Intraoperative enteroscopy in Crohn's disease. Br J Surg 1993;80:897-900

3 Weakley FL, Turnbull RB. Recognition of regional ileitis in the operating room. Dis Colon Rectum 1971;14:17-23.

4 Fazio VW, Jones IT. Standard surgical treatment of Crohn's disease of the small intestine and ileocolitis. In: Lee ECG, Nolan DJ, eds. Surgery of inflammatory bowel disorders. Edinburgh: Churchill Livingstone, 1987: 147-56.

5 Borley NR, Mortensen NJ, Jewell DP, et al. The relationship between inflammatory and serosal connective tissue changes in ileal Crohn's disease: evidence for a possible causative link. J Pathol 2000;190:196-202.

6 Maeda K, Okubo K, Shimomura I, et al. cDNA cloning and expression of a novel adipose specific collagen-like factor, apM1 (Adipose Most abundant Gene transcript 1). Biochem Biophys Res Commun 1996;221:286-9.

7 Yokota T, Oritani K, Takahashi I, et al. Adiponectin, a new member of the family of soluble defense collagens, negatively regulates the growth of myelomonocytic progenitors and the functions of macrophages. Blood 2000;96:1723-32.

8 Holmskov U, Malhotra R, Sim RB, et al. Collectins: collagenous C-type lectins of the innate immune defense system. Immunol Today 1994;15:67-74.

9 Epstein J, Eichbaum Q, Sheriff S, et al. The collectins in innate immunity. Curr Opin Immunol 1996;8:29-35.

10 Lu J. Collectins: collectors of microorganisms for the innate immune system. Bioessays 1997; 19:509-18.

11 Yamauchi T, Kamon J, Waki H, et al. The fat-derived hormone adiponectin reverses insulin resistance associated with both lipoatrophy and obesity. Nat Med 2001;7:941-6.

12 Maeda N, Shimomura I, Kishida K, et al. Diet-induced insulin resistance in mice lacking adiponectin/ACRP30. Nat Med 2002;8:731-7.

13 Weyer C, Funahashi T, Tanaka S, et al. Hypoadiponectinemia in obesity and type 2 diabetes: close association with insulin resistance and hyperinsulinemia. J Clin Endocrinol Metab 2001;86:1930-5.

14 Okamoto Y, Kihara S, Ouchi N, et al. Adiponectin reduces atherosclerosis in apolipoprotein E-deficient mice. Circulation 2002;106:2767-70.

15 Yamauchi T, Kamon J, Waki H, et al. Globular adiponectin protected ob/ob mice from diabetes and ApoE-deficient mice from atherosclerosis. J Biol Chem 2003;278:2461-8.

16 Ouchi N, Kihara S, Arita Y, et al. Adipocyte-derived plasma protein, adiponectin, suppresses lipid accumulation and class $A$ scavenger receptor expression in human monocyte-derived macrophages. Circulation 2001;103:1057-63

17 Arita $Y$, Kihara S, Ouchi N, et al. Adipocyte-derived plasma protein adiponectin acts as a platelet-derived growth factor-BB-binding protein and regulates growth factor-induced common postreceptor signal in vascular smooth muscle cell. Circulation 2002;105:2893-8.

18 Xu A, Wang Y, Keshaw H, et al. The fat-derived hormone adiponectin alleviates alcoholic and nonalcoholic fatty liver diseases in mice. J Clin Invest 2003;112:91-100.

19 Kamada Y, Tamura S, Kiso S, et al. Enhanced carbon tetrachloride-induced liver fibrosis in mice lacking adiponectin. Gastroenterology 2003;125:1796-807

20 Ouchi N, Kihara S, Arita Y, et al. Novel modulator for endothelial adhesion molecules: adipocyte-derived plasma protein adiponectin. Circulation 1999; 100:2473-6.
21 Wulster-Radcliffe MC, Ajuwon KM, Wang J, et al. Adiponectin differentially regulates cytokines in porcine macrophages. Biochem Biophys Res Commun 2004;316:924-9

22 Ouchi N, Kihara S, Arita Y, et al. Adiponectin, an adipocyte-derived plasma protein, inhibits endothelial NF-kappaB signaling through a cAMP-dependent pathway. Circulation 2000;102:1296-301.

23 Kumada M, Kihara S, Ouchi N, et al. Adiponectin specifically increased tissue inhibitor of metalloproteinase-1 through interleukin-10 expression in human macrophages. Circulation 2004;109:2046-9.

24 Ouchi N, Kihara S, Funahashi T, et al. Reciprocal association of C-reactive protein with adiponectin in blood stream and adipose tissue. Circulation 2003; 107:671-4

25 Sewter CP, Digby JE, Blows F, et al. Regulation of tumour necrosis factoralpha release from human adipose tissue in vitro. J Endocrinol $1999 ; 163: 33-8$.

26 Herlinger H, Furth EE, Rubesin SE. Fibrofatty proliferation of the mesentery in Crohn disease. Abdom Imaging 1998;23:446-8.

27 Knutson H, Lunderquist A, Lunderquist A. Vascular changes in Crohn's disease. Am J Roentgenol Radium Ther Nucl Med 1968;103:380-5.

28 Yamauchi T, Kamon J, Waki H, et al. The mechanisms by which both heterozygous peroxisome proliferator-activated receptor gamma (PPARgamma) deficiency and PPARgamma agonist improve insulin resistance. J Biol Chem 2001;276:41245-54.

29 Desreumaux P, Ernst O, Geboes K, et al. Inflammatory alterations in mesenteric adipose tissue in Crohn's disease. Gastroenterology 1999; 117:73-81.

30 Brun RP, Kim JB, Hu E, et al. Peroxisome proliferator-activated receptor gamma and the control of adipogenesis. Curr Opin Lipidol 1997;8:212-18.

31 Spiegelman BM, Flier JS. Adipogenesis and obesity: rounding out the big picture. Cell 1996;87:377-89

32 Okuno A, Tamemoto $\mathrm{H}$, Tobe $\mathrm{K}$, et al. Troglitazone increases the number of small adipocytes without the change of white adipose tissue mass in obese Zucker rats. J Clin Invest 1998;101:1354-61.

33 Maeda N, Takahashi M, Funahashi T, et al. PPARgamma ligands increase expression and plasma concentrations of adiponectin, an adipose-derived protein. Diabetes, 2001;50:2094-9.

34 Combs TP, Wagner JA, Berger J, et al. Induction of adipocyte complementrelated protein of 30 kilodaltons by PPARgamma agonists: a potential mechanism of insulin sensitization. Endocrinology 2002;143:998-1007.

35 Shibata T, Kondo M, Osawa T, et al. 15-deoxy-delta 12, 14-prostaglandin J2. A prostaglandin D2 metabolite generated during inflammatory processes. J Biol Chem 2002;277:10459-66.

36 Forman BM, Tontonoz P, Chen J, et al. 15-Deoxy-delta 12, 14-prostaglandin $\mathrm{J} 2$ is a ligand for the adipocyte determination factor PPAR gamma. Cell 1995;83:803-12.

37 Kliewer SA, Lenhard JM, Willson TM, et al. A prostaglandin J2 metabolite binds peroxisome proliferator-activated receptor gamma and promotes adipocyte differentiation. Cell 1995;83:813-19.

38 Arita Y, Kihara S, Ouchi N, et al. Paradoxical decrease of an adipose-specific protein, adiponectin, in obesity. Biochem Biophys Res Commun 1999;257:79-83.

39 Heinrich PC, Castell JV, Andus T. Interleukin-6 and the acute phase response. Biochem J 1990;265:621-36.

40 Bataille R, Klein B. C-reactive protein levels as a direct indicator of interleukin6 levels in humans in vivo. Arthritis Rheum 1992;35:982-4.

41 Barbier M, Vidal H, Desreumaux P, et al. Overexpression of leptin mRNA in mesenteric adipose tissue in inflammatory bowel diseases. Gastroenterol Clin Biol 2003;27:987-91

\section{EDITOR'S QUIZ: GI SNAPSHOT}

\section{Answer}

From question on page 768

The computed tomography (CT) scan shows intrahepatic gas with linear branching at the periphery, suggestive of gas in the portal venous system (fig 1). In addition, the sigmoid colon appears thick walled and abnormal (fig 2). This is different from air in the biliary tree (pneumobilia) where the low attenuation is central due to centripetal flow of bile.

On the basis of the CT findings, the patient underwent emergency laparotomy. An inflammatory mass involving the sigmoid colon was found. The liver appeared congested and mottled but the gall bladder was normal. The sigmoid colon was resected with end transverse colostomy formation. Postoperative recovery was unremarkable.

The presence of portal venous gas is not in itself a predictor of mortality; the clinical context is a more relevant prognosticator. Numerous conditions have been associated with its development, with no cause found in $15 \%$ of cases. Most can be managed nonoperatively. However, surgical intervention is recommended in mesenteric ischaemia.

doi: 10.1136/gut.2004.057729 